\title{
Fracking Frames and the Courts
}

Ole W Pedersen* and Anthony R. Zito**

Final version to be published in 20(4) Environmental Law Review (2018) available on http://journals.sagepub.com/home/elj

\begin{abstract}
This article utilises the concept of policy framing to examine regulatory choices and the contestation of such choices in the context of hydraulic fracturing in the UK. The article makes no argument about the merits of fracking in the UK context, but rather explores how the institutional choices and design serve to shape the legal reasoning, thereby defining the ability of actors outside the London government to engage with its efforts to govern. Through the lens of recent judicial decisions in which claimants have sought to challenge privileged policy frames supportive of hydraulic fracturing, the article finds that the deferential approach taken by the courts serves to reinforce privileged frames, resulting in there being little scope to challenge such frames.
\end{abstract}

Keywords: hydraulic fracturing, framing, climate change, courts, judicial review.

\section{INTRODUCTION}

The United Kingdom finds itself at the frontier in Europe for the extraction of shale gas reserves through the process of hydraulic fracturing, better known as 'fracking'. ${ }^{1}$ While the rest of the European Union (EU) has moved away from a focus on fracking due to political choice or the absence of viable shale reserves, ${ }^{2}$ the UK government has gone ahead with a position

\footnotetext{
*Newcastle Law School, ole.pedersen@ncl.ac.uk.

** Newcastle University School of Geography, Politics and Sociology, anthony.zito@newcastle.ac.uk.

1 This research was carried out as part of the ReFINE research consortium led by Newcastle and Durham Universities. ReFINE has been funded by Ineos, Shell, Chevron, Total, GDF Suez, Centrica, and NERC. We thank the ReFINE Independent Science Board for prioritising the research projects undertaken by ReFINE and we acknowledge the research support of our Research Assistant, Anna Maclean.

${ }^{2}$ A useful summary of the most current EU member state positions can be found in the individual member state responses about the measures their governments had taken in response to the Commission Recommendation 2014/70/EU. See the website http://ec.europa.eu/environment/integration/energy/unconventional en.htm (accessed March 16 2018).
} 
supporting the exploration of shale production with the aim of tapping this energy system. ${ }^{3}$ In the context of the economic impact of the post 2007 global recession as well as the political and economic uncertainties of the UK relationship to the EU, the Cameron and May governments have promoted a national strategy to stimulate this industry in the face of considerable opposition from both the general public ${ }^{4}$ and devolved governments and local authority governments. ${ }^{5}$ Nevertheless, the nature of the national unitary institutional and electoral systems has enabled the government to push through this opposition and reinforce fracking efforts in England. ${ }^{6}$

The lack of a national consensus means that there is an important story to tell about how the battle will be continue between the government position and the range of opposing groups. The purpose of this article is to explain the role of the UK courts in determining whether the government's definition of the fracking issue and its strategic plan can overcome attempts to oppose the government stance and preferences. In the efforts to decide fracking cases, the UK courts are not merely ruling on administrative procedures but rather deciding what scope critics of the government policy have to challenge fracking decision-making, ultimately legitimising the policy preferences contained in the UK regulatory approach to fracking. Consequently judicial decisions have the ability to shape the future policy debate over fracking within the UK as well as the degree of societal engagement with the decision-making process.

The article's structure proceeds as follows. The next section lays out the insights that the concept of policy framing provides for legal analysis. In particular the policy framing approach stresses the importance in how all legal and policy actors define the issue and the solutions that flow from that definition. While there is always a possibility for rational consensus-building, the likelihood of an issue involving high visibility and strongly contrasting policy views is one that will see conflict. The core analytical insight of this piece is to stress how policy framing can be used to limit policy debate and the contestation about administrative decisions. The recent court cases examined in this article suggest that the courts will play a

\footnotetext{
3 See also Arthur Nelsen, 'The rise and fall of fracking in Europe', The Guardian, 29.9.16, https://www.theguardian.com/sustainable-business/2016/sep/29/fracking-shale-gas-europe-opposition-ban (accessed March 16 2018).

4 William Jordan, 'Public Opposition to Fracking Grows', 19.5.17, https://yougov.co.uk/news/2015/05/19/opposition-fracking-britain-grows/ (accessed March 16 2018).

${ }^{5}$ Both the Wales Assembly and the Scottish Assembly have instituted moratorium on fracking; see for example, 'Fergus Ewing Announces Moratorium on Fracking', http://www.fergusewing.com/fergus-ewing-announcesmoratorium-on-fracking/ http://www.fergusewing.com/fergus-ewing-announces-moratorium-on-fracking/.

${ }^{6}$ John TS Keeler, 'The Politics of Shale Gas and Anti-fracking Movements in France and the UK' in Yongsheng Wang and William E. Hefley (eds.), The Global Impact of Unconventional Shale Gas Development (Springer 2016), 66-68.
} 
limited role in broadening the scope of conflict and opposition to the UK's administrative approach to hydraulic fracturing, as well as the possibilities for societal actors to counter this approach. In a sense, the finding that the courts play a limited role in supervising administrative decision-making is neither revolutionary nor new. In supervising policy choices and administrative decisions giving force to such choices, the courts have traditionally maintained a principled focus on matters of legality. The point brought home in this article is that this focus severely restricts the scope afforded to those seeking to challenge fracking decisions.

The third section provides an overview of the aspects of the UK regulatory regime that are most critical to understanding how the UK administration has framed the UK approach to fracking. Particular attention is paid to the institutional choices that define the participation in governing this policy area and how that definition may restrain the voice of those actors holding different frames.

The fourth section reviews two recent cases in the UK legal context. ${ }^{7}$ The two cases have been selected because they engage with particular framings of hydraulic fracturing and its regulation; these framings define the decisional outcome and the societal scope to object to the regulatory decision. This article makes no argument about the merits of fracking in the UK context, but rather explores how the institutional choices and design serve to shape the legal reasoning, thereby defining the ability of actors outside the London government to engage with its efforts to govern.

\section{FRAMING CONTESTATION: AN ANALYTICAL APPROACH}

Public policy and some legal scholars use the concept of policy framing to understand how different social/political actors manage to grasp and act upon complex situations. ${ }^{8}$ The policy framing process involves our protagonists (a) confronting a situation where the knowledge is uncertain and potentially contested; (b) building an understanding or narrative that enables these actors to assess the situation, and (c) then taking action and potentially persuading others to do likewise. ${ }^{9}$ Inherent in the framing approach is the reality that different individuals and

\footnotetext{
${ }^{7}$ The first is $R$ (Friends of the Earth Anor) $v$ North Yorkshire County Council [2016] EWHC 3303 (Amin), and the second is Preston New Road Action Group v Secretary of State for Communities \& Anor [2018] EWCA Civ 9.

${ }^{8}$ For the most notable application in the UK fracking context, see Chris Hilson, 'Framing Fracking: Which Frames are heard in English Planning and Environmental Policy and Practice?' (2015) 27(2) JEL 181-183. See also Matthew Cotton, Imogen Rattle and James Van Alstine, 'Shale Gas Policy in the United Kingdom: An Argumentative Discourse Analysis' (2014) 73 Energy Policy 427-438, approaching fracking debates from the perspective of discourse theory,

9 David Snow and Robert Benford, 'Ideology, Frame Resonance, and Participant Mobilization' (1988) 1(1) International Social Movement Research, 197-217.
} 
groups can view the same social and natural phenomena and produce different conclusions and reasoning. Integral in the framing of any policy or legal problem is an assessment of the potential roles of other involved parties; consequently framing will define the degree to which other potential actors are included and benefit from the policy/legal process and decisions. This sets up a potential contestation as the resulting marginalized groups may contest the framing and perhaps even offer their alternative ('counter') frame. The argument of this section is that how framing occurs will shape the legal and political opportunities and the scope for contestation by different actors involved in the fracking issue.

Schön and Rein focus their discussion of policy framing on the reality that conflicting policy frames will exist in most modern policy areas. ${ }^{10}$ These frames involve stories or structures of understanding that human belief and perception have created. When confronted by a contested and/or uncertain policy problem, diverse elements of society focus upon different elements and linkages between these elements to build substantially dissimilar perceptions of reality. Often these frames are tacit in nature, which partially explains the difficulty of reconciling different frames as the competing frame proponents lack the ability to actively scrutinise and judge the contrasting frames. In order to gather support, these frames must have resonance with a wider group of actors in order to attract resources and build coalitions of actors with like-minded interests and approaches. ${ }^{11}$

Tacit or not, these frames are critical in defining what is the interest of the different actors in the policy sector. The linkage between frames and interests is what galvanises action and support on behalf of the frames, and it reinforces the potential for contestation. For Schön and Rein, such differences will manifest themselves in a contested dialogue that will involve two forms of discourse. ${ }^{12}$ The first discourse involves the different actors seeking to prevail with their policy stories in a particular policy domain, using persuasion, evidence and other rhetorical means. ${ }^{13}$ The second discourse involves contestation over the policy practice that should follow -i.e. actors develop the policy stories that influence the creation of procedures, specific policy tools et cetera that will deliver the policy. This is an important distinction as the British policy discussion involves not simply a definition of the issue of fracking but a

\footnotetext{
${ }^{10}$ Donald Schön, and Martin Rein, Frame Reflection: Toward the Resolution of Intractable Policy Controversies (Basic Books 1994).

${ }^{11}$ William A Mirola, 'Asking for Bread, Receiving a Stone: The Rise and Fall of Religious Ideologies in Chicago's Eight-hour Movement' (2003) 50(2) Social Problems 273-293.

${ }^{12}$ Schön and Rein above n 10, 28-32.

${ }^{13}$ E.g. Ole W Pedersen, 'The Rhetoric of Environmental Reasoning and Responses as Applied to Fracking' (2015) 27 JEL 325-334.
} 
consideration of what are the correct procedures, policy instruments and who is involved in these procedures and instruments.

Schön and Rein theorise that a process of reflection about the frames, where actors learn more about their actions and the consequences of their actions may lead to a process of learning and 'reframing', in which actors use reflection and discourse in a way that leads to a rational, consensual resolution of the policy dispute. ${ }^{14}$ Nevertheless, they accept that this is only one possibility for dealing with contention. Actors may opt for an escalation of the struggle, by seeking to re-package the object of their frame to accommodate and make alliances with the like-minded interests of other actors operating in the policy sector, or by working out some political compromise, emphasising give and take, which can satisfy the opposing parties. ${ }^{15}$

While all of these possibilities are true, the fracking policy problem in the UK context has a number of elements that make the more rational compromises less tractable. ${ }^{16}$ One dimension is the continuing policy uncertainty considering the implications of the fracking operations for UK communities and the environment more generally. As indicated before, this allows the possibility of multiple frames and enhances the difficulty in reconciling these frames. Second, the competing groups have frames with some fundamental differences in their 'meta-narratives' (the overarching values and perspectives on how the world works and should work), for instance whether the best response to the ongoing problem of climate change is the speediest possible abandonment of fossil fuel extraction. Finally, the impact and costs of hydraulic fracturing extraction and shipment operations generate a relatively high cost-benefit dynamic for particular groups of societal actors, unlike the more diffuse policy problems such as climate change. ${ }^{17}$ The high visibility of such activities as well as the other characteristics challenge the possibilities of resolution through rational, technocratic discussions. The likely outcome is a contestation between coalitions wielding different frames.

Elmer Schattschneider captures this dynamic in arguing that all political contestation involves the question of the 'scope of conflict', which reflects the number of actors involved in a policy debate. ${ }^{18}$ When there are a relatively limited number of players in a policy solution, it is much more likely that those actors with an advantage in resources, whether administrative authority, knowledge, finance and so forth, will overcome the other parties in the debate.

\footnotetext{
${ }^{14}$ Schön and Rein above n 10, 170-172, 186-187.

${ }^{15}$ Ibid., 170-171.

${ }^{16}$ Claudio M. Radaelli, 'Technocracy in the European Union’ (Addison Wesley Longman 1999).

17 Fedor A Dokshin, 'Whose Backyard and What's at Issue? Spatial and Ideological Dynamics of Local Opposition to Fracking in New York State, 2010 to 2013' (2016) 81(5) American Sociological Review 921-948. 18 Elmer E Schattschneider, The Semi-Sovereign People: A Realist's View of Democracy in America (Holt, Rinehart and Winston 1975) 2-5.
} 
Things become much less certain when a greater range of actors join into the situation; here the actors in the dominant position may lose control of the situation and the policy debate. Thus the political game becomes one where actors seek to control the scope of conflict. Those who favour the status quo on a given policy question will have a considerable interest in limiting the scope of conflict and the number of participants. ${ }^{19}$ Those actors who are engaged in the debate but feel they are losing the issue or those excluded from this debate have a considerable incentive to widen the participation in the debate.

Framing of the policy problem and solution becomes a core element of this contestation over the scope of conflict. Thus, any given policy sector will see coalitions of actors seeking to make their particular frame the dominant one in addressing the policy problem, while keeping opposing frames, or counter-framing, in a highly marginalised position. The origins of the framing concept in the study of social movements have tended to give less attention to elite framing with the assumption that these are rather fixed and static arenas that social movements seek to penetrate. However, there is an ongoing and evolving engagement between the state and society that needs further elaboration. Noakes argues for the importance of understanding the role 'official frames' can have in both mobilising elements of society to support positions and to counter alternative voices. ${ }^{20}$ Noakes suggests that state actors will draw on an established repertoire of frames but may also seek to adapt new framings in order to maintain legitimacy and preserve authority over society. ${ }^{21}$ These framings, together with the ability to deploy legal/administrative authority as well as allocative resources can lead to the official frame being dominant to the exclusion or varying degree of marginalisation of other potential counterframings.

In light of recent judicial decisions on fracking, this article examines the extent to which existing UK regulatory frames impact on the ability of critics to challenge these existing frames. That is, what avenues are available to critics in the attempt to challenge existing regulatory frames? Further, to the extent critics are able to promote counter-frames, how are these engaged with by the courts? Before examining the relevant cases in detail, the section below sets out an overview of the regulatory regime and institutional choices relating to fracking.

\footnotetext{
${ }^{19}$ Ibid., 4-5.

${ }^{20}$ John A Noakes, 'Official Frames in Social Movement Theory: The FBI, HUAC, and the Communist Threat in Hollywood' (2000) 41(4) The Sociological Quarterly 658-659.

${ }^{21}$ Ibid., 669-670.
} 


\section{FRACKING REGULATION IN THE UK}

The regulatory system in place for fracking in the UK is a complex and multi-layered arrangement, engaging several separate regimes and regulatory authorities. At the heart of the regulatory approach stands the decision by the government to engage in regulation of environmental risks arising from fracking activities primarily through the use of existing regulatory structures (notwithstanding calls for the need for explicit and tailored regimes) alongside a strong political support for fracking. ${ }^{22}$ Together this support and emphasis on existing regulatory regimes give rise to a regulatory system with the ultimate aim to advance the extraction of oil and gas through fracking. ${ }^{23}$ That is, the institutional and regulatory choices which are manifested in the regulatory regime for fracking ultimately serve to give force to this underlying policy assumption in favour of fracking. The core narrative of the frame involves the objective of boosting fracking extraction. The definition of the policy challenge contained in this narrative is balancing the desire to enhance the UK's position in terms of economic prosperity, energy resource capacity and technological advancement against the risks involved in the extraction and production processes. ${ }^{24}$ The government frame views these risks as being containable in the current regulatory and planning processes (solution discourse). This official frame sharply contrasts with a key counter-frame often advanced by opponents of fracking, who argue that fracking activities ought to be limited in order to minimise climate change impacts. $^{25}$

Two main features stand out in this regard. First, though some decision-making powers are conferred on local planning authorities, the main regulatory authorities charged with overseeing fracking activities are central or national agencies. These include, at the time of writing, the Oil and Gas Authority (issuing petroleum licenses under the Petroleum Act 1998) and the Environment Agency (overseeing the permits required prior to commencing fracking activities under the Environmental Permitting Regulations (England and Wales) 2016) as well as the Health and Safety Executive (charged with overseeing the safety of a well site). Prior to engaging in fracking operations (be it exploratory or substantial drilling), an operator will thus

\footnotetext{
22 E.g. Joanne Hawkins, 'Fracking: Minding the Gaps' (2015) 17 ELR 8-21.

${ }^{23}$ See Elen Stokes, 'Regulatory Domain and Regulatory Dexterity: Critiquing the UK Governance of Fracking' (2016) 79(6) MLR 961-986, for an analysis of the governance means deployed by the government to achieve this end.

${ }^{24}$ Daniel Nyberg, Christopher Wright and Jaqueline Kirk, 'Fracking the Future: Temporality, Framing and the Politics of Unconventional Fossil Fuels' (2017) 1 Academy of Management Annual Meeting Proceedings and Cotton et al above $\mathrm{n} 8$.

${ }^{25}$ E.g. by Friends of the Earth: https://friendsoftheearth.uk/climate-change/fracking (accessed 16 March 2018).
} 
have to apply for environmental permits from the Environment Agency (in England) for a series of activities related to fracking, including for activities relating to mining waste activities, radioactive substance activities, water discharge activities, groundwater activities, flood risk activities, and for activities relating to the facility itself (e.g. flaring of excess gas and storage of fracking substances on site etc.). ${ }^{26}$

Second, to the extent decision-making takes place outside these centralised agencies, it is significantly constrained in practice by explicit executive decree. Thus, though an operator will have to apply for planning consent from local planning authorities prior to the commencement of drilling under the Town and Country Planning Act 1990, the Government has indicated that it will consider 'actively' calling in planning applications for fracking activities while also promising to identify 'underperforming local planning authorities that repeatedly fail to determine [..] applications within statutory timeframes'. ${ }^{27}$ The strong direction, or 'steer', from the government on local decision-making suggests not only that the onus is on local planning authorities to justify any diversion from the government's stated preference for shale gas exploration, but it is also suggestive of the way in which force is lent to the Government's preferences and favoured official frame (i.e. promoting fracking and seeking to regulated using extant policy tools) by way of regulatory design. One example of this is the emphasis in the planning system on centrally promulgated planning guidance documents. Not surprisingly this policy guidance serves in part to give force to government preferences towards fracking. ${ }^{28}$ Consequently, the Government's preferences are considerably and explicitly strengthened through the institutional choices and regulatory designs through which fracking is regulated.

This strong centralisation has significant potential to impact on the extent to which actors are included in the decision-making process as well as on the likelihood of success of subsequent challenges to administrative fracking decisions. In a different policy context, Lee et al thus demonstrate that, for planning decisions which benefit from strategic government support, there is often limited scope for the public to substantively influence decisions through processes of public participation. ${ }^{29}$ In addition to this, Hilson has demonstrated, specifically in the context of fracking, how existing regulatory systems (as well as frames) serve to privilege

\footnotetext{
${ }^{26}$ Environmental Permitting Regulations (England and Wales) 2016 SI 2016 no 1154.

27 https://www.gov.uk/government/publications/shale-gas-and-oil-policy-statement-by-decc-and-dclg/shale-gasand-oil-policy-statement-by-decc-and-dclg (accessed March 16 2018).

${ }^{28}$ E.g. Planning Practice Guidance: Minerals available on https://www.gov.uk/guidance/minerals (accessed March 16 2018).

${ }^{29}$ Maria Lee et al 'Public participation and Climate Change Infrastructure' (2012) 25(1) JEL 33-62.
} 
certain policy-arguments over others (notably in the context of climate change impacts arising from fracking activities). ${ }^{30}$ In light of this, it is relevant to consider the ability of critics to challenge, i.e. dispute, decisions arising from the existing use of frames and decisions. This is done specifically in the context of two recent decisions delivered by the Planning Court of the Queen's Bench Division and the Court of Appeal, engaging with specific environmental impacts arising out of fracking activities.

Before examining the decisions in detail, a few preliminary points must be made. First, the institutional choices and thereby the mechanisms through which critics can challenge administrative decisions relating to fracking are, as a matter of course, likely to have a significant impact on not only the chance of 'success' but also on what arguments claimants will be able to advance as a matter of law. As will be discussed in more detail below, where opponents of fracking have been unsuccessful in shaping government policy-making and local administrative fracking decisions in the planning system, the main outlet for challenging fracking decisions is the courts. Once the contestation of policy choices moves from the 'political' to the 'legal', limits on what constitutes valid and relevant grounds for a challenge take a different shape insofar as claimants will have to give careful thought to how best to phrase (and frame) their arguments in legal vocabularies. ${ }^{31}$ Obvious as this may be, it must be borne in mind that the 'distinctively legal' focus of the courts necessarily restrains the typology of grounds of challenge (e.g. illegality, irrationality and procedural impropriety) and ultimately the type of arguments available to the claimants. ${ }^{32}$

Concretely, the primary regulatory background through which challenges are likely to be mounted is the planning regime. Ultimately, however, this often means judicial review, given that the planning system does not provide statutory appeal rights to third-parties (the same goes for the Environmental Permitting (England and Wales) Regulations 2016) or on a rare occasion statutory appeals under s. 288 of the Town and Country Planning Act 1990. ${ }^{33}$ This is significant in itself as those seeking to challenge administrative fracking decisions will have to 'fit' any counter-fracking arguments within the parameters of the review and appeal regimes in the form of, first, claims/heads of review and, second, scope of review. In the context

\footnotetext{
${ }^{30}$ Hilson above $\mathrm{n} 8$.

${ }^{31}$ See Ole W Pedersen, 'A Study of Administrative Environmental Decision-Making before the Courts' JEL forthcoming, highlighting the dichotomy between the often politicised nature of environmental law and policy debates and the exclusively legal nature of judicial hearings.

32 Peter Cane, Controlling Administrative Power (CUP 2016) 230. See also E Fisher, B Lange and E Scotford, Environmental Law Text and Materials (OUP 2013), 285-288.

${ }^{33}$ It is widely accepted today that the substantive differences between e.g. a statutory appeal under s. 288 of the Town and Country Planning Act 1990 and judicial review are rather minor. E.g. E v Secretary of State for the Home Department [2004] EWCA Civ 49 per Carnwath LJ [42].
} 
of the former, it may well be that a challenge to an administrative decision taken in pursuance of the planning regime, because of the discretionary and flexible nature of the regime, lends itself better to a claim based on unreasonableness (as opposed to illegality). One problem associated with this particular choice of grounds is that a claim in irrationality is all the more challenging to pull off. ${ }^{34}$ In respect to the scope of review, as is discussed below, the limited scope of review poses acute challenges for those seeking to call into question the government's fracking policy. In these types of challenges, it is evident that the courts engage in a restrained review of planning decisions, striking a tone of deference towards planning authorities. ${ }^{35}$

\section{RECENT JUDICIAL FRACKING DECISIONS}

This section identifies two recent cases in which the a priori supportive framing of fracking, manifesting itself in institutional and regulatory choice and policy design, has served to shape the subsequent judicial outcome. The first decision was delivered by Lang $\mathrm{J}$ in $R$ (Friends of the Earth) Anor v North Yorkshire County Council in which the claimants challenged the grant of planning permission to Third Energy for the exploration and production of gas by way of hydraulic fracturing. ${ }^{36}$ The main argument in the claimants' challenge was that the Council had unlawfully failed to take into account the climate change impacts likely to arise from the exploration and burning of gas at a nearby gas-fired electricity generating power station. ${ }^{37}$ Though Lang $\mathbf{J}$ seemingly accepted that environmental impacts arising from the subsequent and cumulative burning of gas were capable of having 'significant adverse effects' for the purpose of the EIA Directive, ${ }^{38}$ she ultimately found that it was up to the local planning committee to judge the weight to be afforded to these impacts against all other material considerations. ${ }^{39}$ Though this conclusion is entirely in line with established judicial practice when it comes to supervising the exercise of planning judgement and the weighing of material considerations against one another, ${ }^{40}$ Lang J relied on two lines of reasoning to substantiate her

\footnotetext{
${ }^{34}$ Outside the context of planning see e.g. $R$ v Lord Chancellor Ex p. Maxwell [1997] 1 W.L.R. 104 per Henry LJ [109].

${ }^{35}$ E.g. $R$ (Newsmith) v Secretary of State for Environment, Transport \& the Regions [2001] EWHC 74 (Admin) per Sullivan $\mathrm{J}$ (as he then was).

${ }^{36} R$ (Friends of the Earth Anor) v North Yorkshire County Council [2016] EWHC 3303 (Amin). The planning permission was thus awarded for full exploration ('stimulation') as opposed to merely explorative drilling.

${ }^{37}$ An additional point of contention was whether the Council had misdirected itself in law by not requiring that the Third Energy provide a financial bond as cover for long-term environmental impacts.

38 [21].

39 [57].

${ }^{40}$ E.g. $R$ (Zurich Assurance Ltd as Threadneedle Property Investments) v North Lincolnshire Council [2012] EWHC 3708 (Admin) per Hickinbottom J [16] and St Modwen Developments Ltd v Secretary of State for Communities and Local Government \& Ors [2017] EWCA Civ 1643 per Lindblom LJ [6].
} 
findings, highlighting the ultimately limited extent to which critics are able to challenge decisions made within existing regulatory frames and structures.

The first line of reasoning follows necessarily from the focus in the EIA Directive on 'projects' ${ }^{41}$ and the emphasis in the planning system on 'development'. ${ }^{42}$ The planning application granted for the well and thereby the development/project that the claimant sought to challenge necessarily stood apart from the existing gas-fired power station to which the gas was to be piped. As a matter of statutory construction (not to say physical construction), the former was a 'development' whereas the latter was not: 'no development was taking place at [the gas-fired power station $]^{43}$ and the present application sought no increase in the capacity at the power station. ${ }^{44}$ The result of this was that the only extent to which environmental impacts from greenhouse gas emissions were considered was in the context of fugitive emissions from the well itself (which the operator identified as negligible) and any potential minimal impacts from the construction of the well itself - not from the potential and cumulative impact from the generating of electricity. ${ }^{45}$

Second, Lang J, stressed that, where the local planning committee had been made aware of the potential for an increase in greenhouse gas emissions as a result of planning permission being granted to fracking activities, it was up to the committee, as a matter of planning judgement, considering all material considerations, and in light of government policy on shale gas, to decide what weight to afford to such considerations. In other words, the potential impacts were readily identified as potential material considerations with the implication that the actual weight to be afforded to them being a matter of planning judgement for the planning authority. In making this decision, rehearsing a long line of precedent, Lang $\mathbf{J}$ cautioned against judicial interference in matters of planning judgements. ${ }^{46}$

This gives rise to a situation where, as argued by the claimant, cumulative climate change impacts from greenhouse gasses are likely only to be given decisive emphasis by planning authorities in a limited number of circumstances. The circumstances in which the climate change counter frame will receive attention are, first, the unlikely scenario where the gas extracted from a well will be burnt for electricity generation as part of the development itself on site (as opposed to being piped to an existing site), thereby forming part a development

\footnotetext{
41 Directive 2011/92/EU (consolidated version http://ec.europa.eu/environment/eia/pdf/EIA_Directive_informal.pdf ) Art. 2 (accessed March 16 2018).

42 Town and Country Planning Act 1990 Part III.

${ }^{43}$ Preston New Road Action Group v Secretary of State for Communities \& Anor [2018] EWCA Civ 9 [49].

${ }^{44}$ Ibid [39].

${ }^{45}$ Ibid [27], [33]-35].

${ }^{46}$ N. 40 above.
} 
(and EIA projects) for the purposes of the Town and Country Planning Act 1990 and the EIA Directive. The second way in which the cumulative impacts of greenhouse gas emission from shale gas exploration may be taken into account by the local planning authority is, put simply, where the planning committee decides that such secondary impacts are a material consideration (which Lang $\mathrm{J}$ suggests that they might well be) and afford decisive weight to this factor. From Lang J's decision, it seems that North Yorkshire County Council, as a matter of exercising its planning judgement, would have been entitled to find that cumulative climate change impacts ought to have been afforded greater weight, though it ultimately did not. The upshot of this is that the key counter frame (challenging the government's reliance on fracking as a 'bridgefuel') with its emphasis on the long-term environmental impacts arising from the burning of fossil fuels and objective of keeping the natural gas in the ground is given a limited space in which to be aired.

The second of the two recent decisions on which this article focuses is the statutory challenge in Preston New Road Action Group v Secretary of State for Communities \& Anor to the grant of planning permission by the Secretary of State to hydraulic exploratory drilling of wells at Little Plumpton, Lancashire. ${ }^{47}$ A central focus of the claimants' argument centred on the landscape impacts of the well site, thereby relying a 'local environmental destruction' frame. ${ }^{48}$ This 'local environmental destruction' frame contested the claim that landscape impacts were only temporary (as the drilling was exploratory), arguing instead that serious landscape harm may well arise out of drilling activities however short-lived they are. A second line of argument was that the grant of planning permission was unlawful on the grounds that the environmental statement, forming part of the application, did not include potential cumulative climate change impacts from greenhouse gas emissions from subsequent phases of production should the exploration prove to be viable. As with the decision taken by the North Yorkshire County Council, no assessment was made of the likely environmental impacts from greenhouse gas emissions beyond the ones directly associated with the drilling itself (in this case primarily from flaring). In reaching a decision similar to Friends of the Earth, Lindblom LJ who delivered the Court's opinion, endorsed the analogy drawn in the first instance by Dove $\mathrm{J}$ to Lang J's judgment in Friends of the Earth to furnish the argument of the Court.

The application was for a single project aimed exclusively at exploratory drilling and not for any subsequent commercial production of gas. ${ }^{49}$ Only where the exploratory drilling

\footnotetext{
47 [2018] EWCA Civ 9.

${ }^{48}$ E.g. Nyberg, above n 24.

49 Ibid [63].
} 
proved to be viable was commercial production to commence. Importantly, to Lindblom LJ, were commercial production to materialise, it would be a subsequent and separate project subject to a separate approval process, which would have to be assessed on its own planning merits. In this light, the claimant's argument that potential future greenhouse gas emissions ought to be assessed had to fail as any environmental impacts arising from this were not 'indirect, secondary or cumulative' but 'a matter of conjecture' and impossible to assess. ${ }^{50}$ In support of this conclusion, Lindblom LJ drew on planning policy guidance specifically stating that applications for exploratory drilling ought to be assessed on their own merit without taking into account prospective emissions from future 'hypothetical future activities for which consent has not yet been sought, since the further appraisal and production phases will be the subject of separate planning applications and assessments. ${ }^{51}$

Notwithstanding that the two decisions appear similar at first sight, Lindblom LJ's implicit reliance on the Friends of the Earth decision seemingly ignores the very premise on which that decision was reached. As exemplified in Friends of the Earth, the fact that a new planning application and environmental statement are proffered as a result of the drilling moving from the exploratory phase to the production phase does not in and of itself result in the cumulative climate change impacts being singled out for consideration. As noted above, this depends on other subsequent considerations, including whether or not the electricitygenerating facility receiving the shale gas is an existing stand-alone facility or whether it forms part of the development for which an application is submitted (which is unlikely). Consequently, there is no guarantee, as seemingly suggested by Lindblom LJ, that secondary and cumulative environmental impacts from greenhouse gasses are expressly taken into account. Moreover, the assumption that production-stage gas from shale repositories is not 'additional' but likely to simply replace existing gas sources is, while intuitively attractive, perhaps overly simplistic if the purpose is to assess environmental impacts of a given activity. If the so-called shale gas revolution in the USA has proven anything, it is that attempts to predict energy market behaviour are notoriously difficult and fraught with challenges. Consider for example that the US shale gas boom has resulted in a short to medium-term increase in US coal exports to e.g. Europe. ${ }^{52}$ Furthermore, consider the pernicious rebound effect, according

\footnotetext{
${ }^{50}$ Ibid [63]-[64].

${ }^{51}$ Ibid [66] and Planning Practice Guidance: Minerals published by the Government in March 2014 available on https://www.gov.uk/guidance/minerals (accessed March 14 2018). See also Dove J's decision in the first instance: [2017] EWHC 808 (admin) [129].

52 An added consideration is the extent to which cheap natural gas extracted through fracking might replace not just use of coal as an energy source but also renewable sources such as wind power. See e.g. Daniel Raimi, The Fracking Debate (Columbia University Press, 2017) 110.
} 
to which any efficiency gains (in this case in greenhouse gas emissions) are off-set by increases in consumption.

Alternatively, consider the fact that the actual climate forcing of shale gas (and thereby potential environmental impacts) are hotly contested. ${ }^{53}$ Central to this uncertainty is the fact that the real climate change impact of fracking activities are likely to arise not necessarily from additional $\mathrm{CO} 2$ emissions but from the associated and unintended leakage of methane gasses, a much more potent greenhouse gas. ${ }^{54}$ This point is significant considering the relatively scant attention the issue of methane leakage received in the two cases. In Friends of the Earth as well as in Preston New Road Action Group the environmental impacts arising from leakage of methane gasses were not probed beyond what the operators had included in their respective environmental statements. ${ }^{55}$ In Preston New Road Action Group, Cuadrilla's environmental statement suggested that leakage of methane gasses was likely to be minimal and that fugitive emissions would be greatly reduced. One problem associated with this argument, however, is that the rate at which methane leaks from energy production and storage is highly contested; this means that the environmental impacts arising from fugitive greenhouse gasses are not necessarily as straightforward as the environmental statements and ultimately the two judgments suggest. ${ }^{56}$ Consequently, even where shale gas ends up substituting existing gas in the downstream supply chain, the environmental impacts are likely to vary significantly. This point was not considered in detail by either of the two courts.

Taken together, these two decisions illustrate how challenges to the dominant frames, pursued through government policies and institutional choices, are unlikely to succeed before the courts. By insisting that environmental impacts arising from greenhouse gas emissions will be assessed at a later stage, the courts implicitly endorse, the dominant government frame which favours hydraulic fracking at the expense of 'challenger' frames which frame hydraulic fracking by reference to the local environmental impacts and/or climate change impacts. ${ }^{57}$ This is not surprising. In supervising planning decisions the courts have always refrained from

\footnotetext{
${ }^{53}$ Haewon McJeon et al, 'Limited Impact on Decadal-Scale Climate Change from Increased used of Natural Gas' (2014) 514 Nature 482-485.

${ }^{54}$ Raimi above ch. 7.

55 [2016] EWHC 3303 (Amin) [33]-[36] and [2018] EWCA Civ. [70]-[72].

${ }^{56}$ Compare e.g. Anna Karion et al, 'Methane Emissions Estimate From Airborne Measurements over a Western United States Natural Gas Field (2013) 40 (16) Geophysical Research Letters 4393-4397 to Jeff Peischl et al, 'Quantifying atmospheric methane emissions from oil and natural gas production in the Bakken shale region of North Dakota' (2016) 121(10) Journal of Geophysical Research: Atmosphere 6101-6111 as well as Daniel Zavala-Araiza et al, 'Reconciling divergent estimates of oil and gas methane emissions' (2015) 112 (51) Proceedings of the National Academic of Sciences 15597-1560.

${ }^{57}$ Nyberg et al above $\mathrm{n} 24$.
} 
scrutinising planning judgement, weighing different material considerations against one another intensely. ${ }^{58}$ Similarly, the finding is not to be taken to suggest that the approach taken by the Planning Court and the Court of Appeal is wrong in law. On the contrary, planning policy and well established judicial precedent confirm that a planning authority ought to focus on whether the development for which a permission is sought is an acceptable use of land within the confines of the development plan and other material considerations. Moreover, it is well established that, in making this decision, planning authorities are entitled to assume that other environmental impacts (though relevant) will be dealt with by the relevant statutory regimes set up to do so. ${ }^{59}$ Similarly, there is ample authority endorsing judicial restraint in overruling decisions in which planning authorities have exercised planning judgement in striking a balance between competing interests. ${ }^{60}$ The point made here is merely that this deferential approach serves to reinforce existing frames, constraining the ability of critics to dispute the underlying policy assumptions and therefore also specific fracking decisions. In other words, existing frames, given force through institutional and regulatory design, serve to privilege certain lines of authority, restricting the scope for subsequent conflict resolution (at least insofar as this is taken to mean judicial resolution). Those seeking to challenge privileged frames are as a consequence unlikely to find recourse to doing so in the courts. ${ }^{61}$

\section{CONCLUSION}

Scrutiny of recent judicial decisions engaging with fracking suggests that to the extent critics hope to challenge priorities afforded to fracking within existing policy frames, the courts are unlikely to provide a fruitful 'space' for counter-frames to be validated and for groups outside the governing process to expand the scope of conflict. Though the scale of fracking in the UK is still relatively small and the number of judicial challenges emerging is still low, the analysis put forward here suggests that, where existing frames are afforded priority (e.g. a pro-fracking frame set against an anti-fracking frame emphasising climate change impacts) as a matter of political expediency, these frames are likely to restrain the scope for critics to challenge these before independent arbiters like the courts. This is all the more the case when, as is the situation when it comes to decision-making for fracking in the UK, the relevant regulatory systems

\footnotetext{
${ }^{58}$ N. 40 above.

${ }^{59}$ Gateshead MBC v Secretary of State for the Environment [1995] Env LR 37.

${ }^{60}$ E.g. Tesco Stores Ltd v Secretary of State for the Environment [1995] 1 WLR 759.

${ }^{61}$ E.g. Gerald N Rosenberg, The Hollow Hope: Can Courts Bring About Social Change? $2^{\text {nd }}$ ed. (University of Chicago Pres 2008).
} 
afford a major role to the planning system - a system within which the courts have traditionally afforded decision-makers discretionary latitude. Moreover, the analysis suggests that the institutional choices which ultimately lay behind the decision to rely on existing regulatory systems (as opposed to designing an explicit and tailor-made one as many critics favour in the context of fracking) have important impacts on the way in which conflicts are ultimately resolved. ${ }^{62}$

${ }^{62}$ Neil Komesar, Imperfect Alternatives: Choosing Institutions in Law, Economics and Public Policy (University of Chicago Press 1994). 